\title{
Commentary on the article "Pre-treatment with ulipristal acetate before ICSI procedure: a case report" published in Menopause Review 6/2013 (Przeglqd Menopauzalny 2013; 6: 496-500)
}

\section{Artur Wdowiak}

Failure to become and remain pregnant after IVF depends on multiple factors including but not limited to the ability of the uterus to implant embryo and to carry a pregnancy to term. One of the factors which adversely affect fertility is the presence of uterine fibroids [1]. The closer the fibroids are to the uterine cavity, the greater their effect is on female fertility [2]. Reproduction is adversely affected mainly by intramural fibroids, which modulate endometrium and also by submucosal fibroids [2]. In patients with uterine fibroids, the course of pregnancy is often complicated. These are high-risk pregnancies as they may end in miscarriage, premature delivery or intrauterine death [3-5]. The factors predisposing to uterine fibroids include age, African ancestry, obesity and nulliparity. Although studies performed to date have extended our knowledge on fibroid pathology, their etiology has not been fully elucidated. There is a need for further research on predisposing factors and for prevention of uterine fibroids in women. Minimizing invasive treatment becomes the most advisable option, which has been recommended during the Third National Institutes of Health International Congress on Advances in Uterine Leiomyoma Research [6]. Currently, treatment with ulipristal acetate seems the most promising non-invasive treatment option [7-10].

The commented article presents the case of a 35-year-old patient who in June 2012 came to the Non-Public Health Care Unit 'Ovum Reproduction and Andrology' in Lublin to continue the treatment of infertility. Before stimulation for the intracytoplasmic sperm injection (ICSI) procedure, an attempt was made to reduce the fibroid volume with 3-month treatment with Esmya 5 mg $1 \times 1$ given for 84 days. Ultrasound performed after discontinuation of Esmya treatment showed the previously detected intramural fibroid located in the posterior wall, which was found to have a diameter of $1.08 \mathrm{~cm}$, illustrating a reduction from the pre-treatment size and the fibroid located in the front wall of the uterus previously detected by ultrasound was no longer visible.

The next sonographic scan in the $20^{\text {th }}$ week of pregnancy showed normal anatomical structure of the fetus, no fibroid growth in the posterior uterine wall and absence of new fibroids. Between the $24^{\text {th }}$ and $29^{\text {th }}$ weeks of pregnancy, the patient complained of pain in the lower abdomen and periodic uterine contractions.
The cervical length and fibroid size were monitored during check-up visits; the length of the cervix ranged between 3 and $3.5 \mathrm{~cm}$ and no fibroid growth was observed. In per vaginam pelvic examination, the cervix felt soft, closed and it was pointed backwards. Because of these symptoms, spasmolytics and intravaginal progestogens were administered. The symptoms subsided in about $30^{\text {th }}$ week of pregnancy. Sonographic scan in week 30 showed normal anatomical structure of the fetus, biometry consistent with the date of last menstruation, cervical length of $3 \mathrm{~cm}$ and head down position of the fetus. The patient had no complaints past week 30 . Sonography performed in week 36 confirmed normal development and vertex position of the fetus, biometry consistent with the date of last menstruation as well as cervical shortening to $1 \mathrm{~cm}$. In the $38^{\text {th }}$ week of pregnancy, the patient's waters broke and intense contractions started. The baby was delivered in spontaneous labor 11 hours after the breaking of waters; no complications occurred and the baby's Apgar score was 10 (body weight $3158 \mathrm{~g}$ ). The mother lost approx. $250 \mathrm{ml}$ of blood during labor. The patient and her child were discharged from hospital 5 days after delivery; the baby's condition was good. After delivery, the patient reported problems with lactation. She attended a check-up visit 6 weeks after the delivery. Ultrasound examination showed normal size of the uterus, a fibroid with a diameter of $1 \mathrm{~cm}$ located in the posterior wall (Fig. 4), $9.2 \mathrm{~mm}$ thick triple-line endometrium and uterine appendages without visible pathological lesions on either side. The result of blood test performed before the visit was normal, without signs of anemia.

The studies conducted by Capalbo et al. demonstrated that pregnancies obtained through IVF are shorter than those resulting from spontaneous conception and children born through assisted reproductive technology have lower body weight at birth [11]. This may explain why our patient's pregnancy was ended two weeks before term and why she reported pain during pregnancy. Retrospective cohort studies conducted by Lai et al. who compared pregnancies in patients with and without leiomyomas demonstrated that the women with leiomyomas are at a higher risk of preterm delivery and intrauterine death of the fetus [4]. Our patient had both these risk factors. Noor et al. demonstrated a higher percentage of cesarean sections in patients with uter- 
ine fibroids and higher rates of bleeding and anemia after delivery [5]. Eze et al. report similar observations, also pointing to increasingly common premature breaking of waters in patients with uterine fibroids [3].

Hence, the results of studies conducted by Lai et al. [4], Noor et al. [5] and Eze et al. [3] support the need for treating uterine fibroids before planned pregnancy to minimize the risk of complications described above. This medicinal product requires further studies.

To summarize, Esmya treatment does not have any adverse effect on the quality of embryos in the morphological assessment during the ICSI procedure. Pregnancy does not induce changes in fibroid size following earlier treatment with ulipristal acetate. Treatment of uterine fibroids is recommended before planned pregnancy to minimize the risk of obstetric complications.

\section{References}

1. Richards PA, Richards PD, Tiltman AJ. The ultrastructure of fibromyomatous myometrium and its relationship to infertility. Hum Reprod Update 1998; 4: 520-525.

2. Guo XC, Segars JH. The impact and management of fibroids for fertility: an evidence-based approach. Obstet Gynecol Clin North Am 2012; 39: 521-533; doi: 10.1016/j.ogc.2012.09.005.
3. Eze CU, Odumeru EA, Ochie K, et al. Sonographic assessment of pregnancy co-existing with uterine leiomyoma in Owerri, Nigeria. Afr Health Sci 2013; 13: 453-460; doi: 10.4314/ahs.v13i2.36.

4. Lai J, Caughey AB, Qidwai Gl, et al. Neonatal outcomes in women with sonographically identified uterine leiomyomata. J Matern Fetal Neonatal Med 2012; 25: 710-713; doi: 10.3109/14767058.2011.572205.

5. Noor S, Fawwad A, Sultana R, et al. Pregnancy with fibroids and its and its obstetric complication. J Ayub Med Coll Abbottabad 2009; 21: 37-40.

6. Segars JH, Parrott EC, Nagel JD, et al. Proceedings from the Third National Institutes of Health International Congress on Advances in Uterine Leiomyoma Research: comprehensive review, conference summary and future recommendations. Hum Reprod Update 2014; 20: 309-333.

7. Hoellen F, Griesinger G, Bohlmann MK. Therapeutic drugs in the treatment of symptomatic uterine fibroids. Expert Opin Pharmacother 2013; 14: 2079-2085.

8. Islam MS, Protic O, Giannubilo SR, et al. Uterine leiomyoma: available medical treatments and new possible therapeutic options. J Clin Endocrinol Metab 2013; 98: 921-934; doi: 10.1210/jc.2012-3237.

9. Lewis El, Chason RJ, DeCherney AH, et al. Novel hormone treatment of benign metastasizing leiomyoma: an analysis of five cases and literature review. Fertil Steril 2013; 99: 2017-2024; doi: 10.1016/j.fertnstert.2013.01.147.

10. Szamatowicz M, Kotarski J. Selective progesterone receptor modulator (ulipristal acetate - a new option in the pharmacological treatment of uterine fibroids in women). Ginekol Pol 2013; 84: 219-222 [Article in Polish].

11. Capalbo A, Rienzi L, Cimadomo D, et al. Correlation between standard blastocyst morphology, euploidy and implantation: an observational study in two centers involving 956 screened blastocysts. Hum Reprod 2014 [Epub ahead of print]. 